\title{
The integrated stress response in lung disease
}

\author{
Emily F.A. van 't Wout ${ }^{1,2}$, Pieter S. Hiemstra ${ }^{1} \&$ Stefan J Marciniak ${ }^{2 *}$
}

${ }^{1}$ Department of Pulmonology, Leiden University Medical Centre, 2333 ZA Leiden, the Netherlands

${ }^{2}$ Department of Medicine, University of Cambridge, Cambridge Institute for Medical Research

(CIMR), Wellcome Trust/MRC Building, Hills Road, Cambridge, CB2 0XY, UK

* Correspondence should be addressed to:

Dr Stefan J Marciniak

Cambridge Institute for Medical Research (CIMR)

University of Cambridge

Wellcome Trust/MRC Building

Hills Road

Cambridge, CB2 0XY, UK

Phone: $\quad+44(0) 1223762660$

Fax: $\quad+44(0) 1223336827$

e-mail: $\quad$ sjm20@cam.ac.uk

Key words: integrated stress response, ISR, lung, ER-stress

Word count (excluding references and figure legend) $=3989$ (including references, but excluding abstract and legend) 


\begin{abstract}
$\underline{\text { Abstract }}$
Lungs are repeatedly exposed to inhaled toxic insults, such as smoke, diesel exhaust and microbes, which elicit cellular stress responses. The phosphorylation of eIF $2 \alpha$ by one of four stress-sensing kinases triggers a pathway called the integrated stress response (ISR) that helps protect cellular reserves of nutrients and prevents that accumulation of toxic proteins. In this review, we will discuss how activation of the ISR has been shown to play an important role in pulmonary pathology and how its study may help in the development of novel therapies for diverse conditions from hypoxia to cancer.
\end{abstract}




\section{Introduction}

Because of its direct contact with the outside world, the lung is continuously challenged by inhaled insults, including smoke, diesel exhaust and a multitude of microbes, all of which trigger various cellular stress pathways. Recent studies have underlined the critical role played by one of these stress pathways, which involves phosphorylating the alpha subunit of eukaryotic translation initiation factor 2 (eIF2 $\alpha$ ). This single molecular event serves to integrate signalling from multiple stress-sensors and so has been termed the 'integrated stress response' (ISR) (Figure 1). In this review, we will discuss the ISR with particular regard to its evolving role in pulmonary medicine.

\section{The integrated stress response (ISR)}

Activation of the ISR occurs when one of four homologous stress-sensing kinases is triggered (Figure 1) (1). GCN2 evolved first to enable eukaryotes to respond to amino-acid starvation. As multicellular animals developed, GCN2 gave rise to a family of kinases that each respond to different stresses. HRI is responsive to iron-deficiency and other stressful stimuli including oxidation; PKR responds to double-stranded RNA during some viral infections; while, PERK senses the efficiency of protein folding within the endoplasmic reticulum (ER), thus enabling cells to trigger the ISR during ER-stress. This pathway induced by activation of PERK is also one of the three arms of the unfolded protein response (UPR) to ER-stress, which has been reviewed elsewhere (2).

When eIF $2 \alpha$ is phosphorylated, protein synthesis is blocked serving a number of cytoprotective roles. During ER-stress, this slows the rate of proteins entering the ER thereby 
off-loading overburdened chaperones; in conditions of amino-acid starvation or iron limitation, it reduces the rate at which these nutrients are consumed; and during viral infection, blocking protein synthesis impedes viral replication. In addition, phosphorylation of eIF $2 \alpha$ promotes the translation of a subset of mRNAs, most notably that encoding the transcription factor ATF4. Indeed, most ISR target genes are transactivated by ATF4 and help adapt the cell to these stresses. For example, up-regulation of transporters increases amino-acid import, thus overcoming nutrient limitation while providing substrates needed for antioxidant biosynthesis synthesis. ATF4 also induces expression of another transcription factor, CHOP, which cooperates with ATF4 to induce the eIF2 $\alpha$ phosphatase GADD34 (3), which completes a negative feedback loop allowing protein synthesis to recover (Figure 1) (4).

Although CHOP is not strictly a pro-death transcription factor, during chronic stress its induction of GADD34 and the consequent recovery of protein synthesis can contribute to worsening ER stress if the original insult persists (5). In addition, induction of the ER oxidase ERO1 $\alpha$ by CHOP promotes oxidative protein folding, but also generates reactive oxygen species (Figure 1). Finally, CHOP contributes to the induction of pro-inflammatory genes, such as interleukin (IL)-8 (6).

\section{Activation of the ISR in lung pathology}

\section{i. Inhaled toxins}

Oxidative stress caused by exposure to cigarette smoke can trigger the ISR. In vitro studies have shown that cigarette smoke extract induces apoptosis in a CHOP-dependent manner that can be antagonised by antioxidants $(7,8)$. ER-stress appears to be a major 
mediator of the response to cigarette smoke extract because inhibition of the kinase PERK blocks induction of CHOP (7). Consistent with this, heightened levels of ER-stress have been observed within smokers' lungs (9) and COPD patients (10). Even a single cigarette can impair oxidative protein folding in murine lungs through impaired function of the ER enzyme PDI (11).

The gene expression signature associated with COPD includes 98 genes, many of which are targets of ATF4 (12). When ATF4 is overexpressed in epithelial cells in vitro, this COPD gene signature is recapitulated and many of these changes can be reversed by inhaled corticosteroid therapy suggesting that treatments might be targeted to this mechanism in future (12).

When mice are exposed to inhaled particulate pollution or cultured human cells are treated with diesel exhaust particles, ER stress triggers the ISR (13)(14). Since the effects of particulate matter can be antagonised by antioxidants, this too likely reflects oxidative stress (13). In fact, the toxicity of particulates may be mediated by the ISR, since CHOP deficient cells are protected from particulate-induced apoptosis.

It would be wrong to suggest that the ISR is purely toxic during pulmonary oxidative stress or that PERK is the sole kinase involved. For example, when mice are exposed to hyperoxia $\left(95 \% \mathrm{O}_{2}\right.$ ), phosphorylation of eIF2 $\alpha$ does not involve ER-stress (5). Instead, PKR is activated by unknown mechanisms to induce ATF4 and CHOP. In this instance, CHOP is protective since Chop-/- mice reared in $95 \% \mathrm{O}_{2}$ develop more severe lung injury, and even modest hyperoxia $\left(80 \% \mathrm{O}_{2}\right)$ causes higher mortality in CHOP deficient animals (5). The mechanism for this protection is unclear but CHOP appears to prevent increased epithelial permeability. But the complex role of CHOP in hyperoxic lung injury requires more study because in newborn mice hyperoxia-induced bronchopulmonary dysplasia CHOP appears to mediate pathological apoptosis (15). 


\section{ii Intrinsic defects}

Point mutations of secreted proteins can cause ER-stress and activate PERK. Surfactant protein C (SFTPC) secreted by type II pneumocytes is mutated in some cases of familial interstitial lung disease (16). A splice-site mutation $(c .460+1 \mathrm{~A}>\mathrm{G})$ that causes deletion of SFTPC exon4 results in protein misfolding and familial interstitial pneumonia. The SFTPC null mouse has a non-lethal phenotype suggesting that the disease-associated mutations in man may be caused by toxic-gain-of-function. Accordingly, when the $\Delta$ exon 4 mutant is expressed in cells it causes ER-stress and phosphorylation of eIF2 $\alpha$ (17). It remains to be tested, however, whether $C H O P$ or $G A D D 34$ genotype can alter the toxicity of the SFTPC mutants. Although currently only a correlation, it is intriguing that elevated levels of ATF4 and CHOP protein have been detected in lung homogenates and in type II cells from patients with idiopathic pulmonary fibrosis (18). ISR activation might therefore represent a common pathway in interstitial lung disease.

Mutations of the SERPINA1 gene encoding $\alpha_{1}$-antitrypsin can cause its accumulation within the ER, but surprisingly most such mutants fail to cause ER-stress, but instead enhance a cell's susceptibility to further insults (19). Most commonly, $\alpha_{1}$-antitrypsin deficiency results from homozygosity for the $\mathrm{Z}$ allele (Glu342Lys) that destabilises the protein such that most is degraded, but some polymerises within the ER resulting in serum deficiency and early onset emphysema. Approximately $10 \%$ of homozygotes also develop clinically significant liver disease. The increased sensitivity of hepatocytes to ER-stress may be involved, since mice made to express the $\mathrm{Z}$ variant are far more susceptible to developing hepatic fibrosis following bile duct ligation, which causes ER-stress, than are animals expressing wild-type $\alpha_{1}$-antitrypsin (20). In this model, Z-expressing mice show an 
exaggerated ISR with enhanced induction of CHOP (20); and it is known that CHOP expression is essential for cholestasis-induced hepatic fibrosis (21). These effects are dependent on the level of $\mathrm{Z} \alpha_{1}$-antitrypsin expressed by a cell, since primary bronchial epithelial cells, which secrete low levels of $\alpha_{1}$-antitrypsin, fail to achieve concentrations of of $\mathrm{Z} \alpha_{1}$-antitrypsin within their ER to allow polymerisation (22). As a result, in contrast to hepatocytes, airway epithelial cells show no augmentation of CHOP or GADD34 upon a second hit of mild ER-stress (22). Each tissue must therefore be considered individually, since monocytes, another $\alpha_{1}$-antitrypsin-expressing cell, have been reported to display enhanced expression of ATF4 when purified from Z homozygous individuals (23).

\section{iii. Infection}

The lung is exposed daily to many inhaled infectious microorganisms that can trigger the ISR. Viral dsRNA can trigger PKR to inhibit protein translation and impedes viral replication (24). Because of the need to recover translation in order to synthesise inflammatory cytokines, GADD34 is required for an efficient host response as demonstrated by the increased susceptibility of GADD34-deficient cells and mice to viral infection (25). But there is redundancy within the system, for example the coronavirus IBV can activate both PKR and PERK, leading to expression of ATF4 and CHOP (26). Surprisingly, both kinases appear to mediate the cytotoxicity of this infection via CHOP-dependent apoptosis.

Activation of Toll-like receptors (TLRs), specifically TLR3 by dsRNA and TLR4 by lipopolysaccharide (LPS), can also trigger phosphorylation of eIF2 $\alpha$ (24). The mechanism for this is not entirely clear, but may plausibly reflects increased ER activity due to the need to secrete cytokines and antimicrobial peptides upon TLR activation. Interestingly, the ISR shows specific modulation by TLR signalling that goes beyond simple activation. In 
macrophages, when phosphorylation of eIF $2 \alpha$ is induced by other stimuli, for example ERstress, activation of TLR4 by LPS blocks induction of ATF4, CHOP and GADD34 (27). It is now becoming clear how this can be explained. Normally, when eIF2 $\alpha$ is phosphorylated it binds to and inhibits eIF2B, an enzyme responsible for maintaining eIF2 $\alpha$ in its active GTPbound state. Indeed, binding of phospo-eIF2 $\alpha$ to eIF2B is responsible both for the inhibition of translation seen during the ISR and for the up-regulation of ATF4 and CHOP. However, activated TLR4 stimulates eIF2B thus overcoming the effects of eIF2 $\alpha$ phosphorylation (28). It has been proposed that this mechanism may enable cells selectively to inhibit the ISR during chronic ER-stress caused by infection and thus avoid the toxic effects of inducing CHOP and its target GADD34.

But this response can have negative consequences during chronic infection and so may represent a therapeutic target. In cystic fibrosis, most causative mutations of CFTR do not cause robust ER-stress directly because these mutations lie within its cytosolic portion $(29,30)$. But loss of CFTR function leads to the generation of thickened airway mucus with reduced clearance, which is prone to chronic colonisation by bacteria such as Pseudomonas aeruginosa. This induces local ER-stress and can be recapitulated in normal airway epithelia by application of CF mucus directly (30), and explains why primary $\mathrm{CF}$ epithelia recover from ER-stress if allowed to grow in vitro in the absence of colonised mucus (29). It has been noted, however, that the ER-stress seen in models of CF in response to Pseudomonas aeruginosa is deficient in PERK-eIF2 $\alpha$ signalling (31). This may contribute to the chronic inflammation seen in $\mathrm{CF}$, since pharmacological induction of eIF2 $\alpha$ phosphorylation with the drug salubrinal was found to lessen the inflammatory response of CF cells. The mechanism by which ER-stress fails to activate the ISR in this context has not been studied in detail, but may involve the novel TLR-eIF2B pathway introduced above. 
Where on-going translation is essential for efficient immune responses, for example in PKR-activated dendritic cells, a modified ISR is activated in which robust induction of GADD34 prevents significant translational attenuation (32). This and other observations, including those of the TLR-eIF2B pathway, have given rise to the concept of a specific 'microbial stress response', which shares many features of the canonical ISR, but with modifications such as less robust induction of CHOP (reviewed in (24)). However, the induction of components of the ISR, including CHOP, can differ substantially between models, perhaps because of cell type or the stimuli used, and thus many 'flavours' of the ISR may exist. For example, when dendritic cells are challenged either with ER-stress or TLR agonists, efficient induction of CHOP is required for secretion of interleukin (IL-) 23 (33), which appears to contrast with the response elicited by PKR activation. It should also be noted that viruses and bacteria have evolved numerous mechanisms to escape the antimicrobial effects of the ISR. For example, respiratory syncytial virus (RSV) can sequester activated PKR and prevent phosphorylation of eIF2 $\alpha$ (34).

\section{iv. Nutrient stress}

Being the oldest in evolutionary terms, GCN2 is ubiquitous in eukaryotes. In terms of pulmonary pathology, it has been studied most in the context of tumour biology as it functions to match amino-acid supplies with demand, which can be a limiting factor in cancer growth. The induction of ATF4 during nutrient stress promotes the induction of many amino-acid transporters and synthetic enzymes in tumour cells, such as asparagine synthetase (35). As a result, inhibition of the GCN2-ATF4 pathway can reduce proliferation and cell survival (35). This accounts for the up-regulation of GCN2 (both activated and total) in lung cancer samples compared to healthy controls or the surrounding non-tumorous cells (35). 
In addition to limiting the levels of nutrients required for macromolecule biosynthesis, starvation profoundly affects the metabolism of a tumour. A consequence of this is a heightened level of ER-stress that is seen in many hypoxic tumours $(36,37)$. It is therefore unsurprising that ER-stress and the UPR have been implicated in the pathophysiology of solid tumours including human lung cancer (8). Evidence of ER-stress is associated with more aggressive tumours and resistance to chemotherapy (36). As the mediator of eIF2 $\alpha$ phosphorylation during ER-stress, PERK has proved necessary for the growth of larger solid tumours (37) and contributes to resistance to therapy (36). It ensures that protein synthesis remains at a level consistent with the supply of nutrients and energy, and through ISRmediated activation of autophagy it also promotes the recycling of nutrients from old and damaged organelles (38). Under such conditions, the recovery of translation mediated by CHOP and GADD34 would be expected to be toxic. Indeed, loss of GADD34 in tumours may prevent apoptosis and promote cell survival in hypoxic conditions (39) and GADD34 expression correlates with the degree of differentiation of malignant mesothelioma, with lower levels of expression being seen in the more aggressive sarcomatoid subtype (40). It is therefore tempting to speculate that GADD34 may be a tumour suppressor in ER-stressed environments, but this has yet to be tested formally.

\section{Conclusion and future directions}

The progress from understanding the basic biology of the ISR to its role in pulmonary pathology has been dramatic and rapid. The breadth of noxious stimuli to which it responds may hamper efforts to identify which stress or stresses were the original insult in some diseases; however, the very fact that multiple kinases converge on a single substrate to regulate translation during disease offers many advantages for research and treatment. If 
selectivity is required, identification of the upstream kinase should offer this, while modulation of the downstream phosphatase(s) can generate a more broad effect. But many unknowns remain, which will make the ISR an exciting and fruitful area for respiratory research for many years to come.

\section{Figure legend}

Figure 1. The integrated stress response (ISR) in the lung.

Phosphorylation of eIF2 $\alpha$ by the stress-sensing kinases GCN2, PKR, PERK or HRI, leads to activation of the ISR by a wide range of insults including amino-acid starvation, viral infection, protein misfolding and iron deficiency. This attenuates global protein synthesis via the inhibition of eIF2B, which normally functions to maintain the translation initiation factor eIF2 in its active GTP-bound state. Simultaneously, limiting levels of active (GTP-bound) eIF2 lead to the translation of the transcription factor ATF4. Targets of ATF4 include aminoacid transporter and synthesases, which serve a cytoprotective role. Via induction of the transcription factor $\mathrm{CHOP}$ and the eIF2 $\alpha$ phosphatase GADD34, ATF4 also promotes the recovery of protein synthesis and oxidative protein folding (through induction of the oxidase ERO1 $\alpha$ ). During severe or prolonged stress, the recovery of protein translation and protein oxidation can contribute to the failure of homeostasis and ultimately to cell death. COPD, chronic obstructive pulmonary disease. 
1. Dalton LE, Healey E, Irving J, Marciniak SJ. Phosphoproteins in stress-induced disease. Progress in molecular biology and translational science 2012; 106: 189-221.

2. Marcinak SJ, Ron D. The unfolded protein response in lung disease. Proceedings of the American Thoracic Society 2010; 7: 356-362.

3. Marciniak SJ, Yun CY, Oyadomari S, Novoa I, Zhang Y, Jungreis R, Nagata K, Harding HP, Ron D. CHOP induces death by promoting protein synthesis and oxidation in the stressed endoplasmic reticulum. Genes \& development 2004; 18: 3066-3077.

4. Novoa I, Zeng H, Harding HP, Ron D. Feedback inhibition of the unfolded protein response by GADD34-mediated dephosphorylation of eIF2alpha. The Journal of cell biology 2001; 153: 1011-1022.

5. Lozon TI, Eastman AJ, Matute-Bello G, Chen P, Hallstrand TS, Altemeier WA. PKRdependent CHOP induction limits hyperoxia-induced lung injury. American journal of physiology Lung cellular and molecular physiology 2011; 300: L422-429.

6. Vij N, Amoako MO, Mazur S, Zeitlin PL. CHOP transcription factor mediates IL-8 signaling in cystic fibrosis bronchial epithelial cells. American journal of respiratory cell and molecular biology 2008; 38: 176-184.

7. Tagawa Y, Hiramatsu N, Kato H, Sakoh T, Nakajima S, Hayakawa K, Saito Y, Johno H, Takahashi S, Gu L, Yao J, Kitamura M. Induction of CCAAT/enhancer-binding protein-homologous protein by cigarette smoke through the superoxide aniontriggered PERK-eIF2alpha pathway. Toxicology 2011; 287: 105-112.

8. Jorgensen E, Stinson A, Shan L, Yang J, Gietl D, Albino AP. Cigarette smoke induces endoplasmic reticulum stress and the unfolded protein response in normal and malignant human lung cells. BMC Cancer 2008; 8: 229. 
9. Kelsen SG, Duan X, Ji R, Perez O, Liu C, Merali S. Cigarette smoke induces an unfolded protein response in the human lung: a proteomic approach. Am J Respir Cell Mol Biol 2008; 38: 541-550.

10. Malhotra D, Thimmulappa R, Vij N, Navas-Acien A, Sussan T, Merali S, Zhang L, Kelsen SG, Myers A, Wise R, Tuder R, Biswal S. Heightened endoplasmic reticulum stress in the lungs of patients with chronic obstructive pulmonary disease: the role of Nrf2-regulated proteasomal activity. American journal of respiratory and critical care medicine 2009; 180: 1196-1207.

11. Kenche H, Baty CJ, Vedagiri K, Shapiro SD, Blumental-Perry A. Cigarette smoking affects oxidative protein folding in endoplasmic reticulum by modifying protein disulfide isomerase. FASEB journal : official publication of the Federation of American Societies for Experimental Biology 2013; 27: 965-977.

12. Steiling K, van den Berge M, Hijazi K, Florido R, Campbell J, Liu G, Xiao J, Zhang X, Duclos G, Drizik E, Si H, Perdomo C, Dumont C, Coxson HO, Alekseyev YO, Sin D, Pare P, Hogg JC, McWilliams A, Hiemstra PS, Sterk PJ, Timens W, Chang JT, Sebastiani P, O'Connor GT, Bild AH, Postma DS, Lam S, Spira A, Lenburg ME. A dynamic bronchial airway gene expression signature of chronic obstructive pulmonary disease and lung function impairment. American journal of respiratory and critical care medicine 2013; 187: 933-942.

13. Laing S, Wang G, Briazova T, Zhang C, Wang A, Zheng Z, Gow A, Chen AF, Rajagopalan S, Chen LC, Sun Q, Zhang K. Airborne particulate matter selectively activates endoplasmic reticulum stress response in the lung and liver tissues. American journal of physiology Cell physiology 2010; 299: C736-749. 
14. Jung EJ, Avliyakulov NK, Boontheung P, Loo JA, Nel AE. Pro-oxidative DEP chemicals induce heat shock proteins and an unfolding protein response in a bronchial epithelial cell line as determined by DIGE analysis. Proteomics 2007; 7: 3906-3918.

15. Choo-Wing R, Syed MA, Harijith A, Bowen B, Pryhuber G, Janer C, Andersson S, Homer RJ, Bhandari V. Hyperoxia and interferon-gamma-induced injury in developing lungs occur via cyclooxygenase-2 and the endoplasmic reticulum stressdependent pathway. American journal of respiratory cell and molecular biology 2013; 48: 749-757.

16. Lawson WE, Cheng DS, Degryse AL, Tanjore H, Polosukhin VV, Xu XC, Newcomb DC, Jones BR, Roldan J, Lane KB, Morrisey EE, Beers MF, Yull FE, Blackwell TS. Endoplasmic reticulum stress enhances fibrotic remodeling in the lungs. Proceedings of the National Academy of Sciences of the United States of America 2011; 108: 10562-10567.

17. Maguire JA, Mulugeta S, Beers MF. Multiple ways to die: delineation of the unfolded protein response and apoptosis induced by Surfactant Protein C BRICHOS mutants. The international journal of biochemistry \& cell biology 2012; 44: 101-112.

18. Korfei M, Ruppert C, Mahavadi P, Henneke I, Markart P, Koch M, Lang G, Fink L, Bohle RM, Seeger W, Weaver TE, Guenther A. Epithelial endoplasmic reticulum stress and apoptosis in sporadic idiopathic pulmonary fibrosis. American journal of respiratory and critical care medicine 2008; 178: 838-846.

19. Ordonez A, Snapp EL, Tan L, Miranda E, Marciniak SJ, Lomas DA. Endoplasmic reticulum polymers impair luminal protein mobility and sensitize to cellular stress in alpha1 -antitrypsin deficiency. Hepatology (Baltimore, Md) 2013; 57: 2049-2060. 
20. Mencin A, Seki E, Osawa Y, Kodama Y, De Minicis S, Knowles M, Brenner DA. Alpha1 antitrypsin $\mathrm{Z}$ protein (PiZ) increases hepatic fibrosis in a murine model of cholestasis. Hepatology (Baltimore, Md) 2007; 46: 1443-1452.

21. Tamaki N, Hatano E, Taura K, Tada M, Kodama Y, Nitta T, Iwaisako K, Seo S, Nakajima A, Ikai I, Uemoto S. CHOP deficiency attenuates cholestasis-induced liver fibrosis by reduction of hepatocyte injury. American journal of physiology Gastrointestinal and liver physiology 2008; 294: G498-505.

22. Van't Wout EF, Dickens JA, van Schadewijk A, Haq I, Kwok HF, Ordonez A, Murphy G, Stolk J, Lomas DA, Hiemstra PS, Marciniak SJ. Increased ERK signalling promotes inflammatory signalling in primary airway epithelial cells expressing $\mathrm{Z}$ alpha1antitrypsin. Human molecular genetics 2013.

23. Carroll TP, Greene CM, O'Connor CA, Nolan AM, O'Neill SJ, McElvaney NG. Evidence for unfolded protein response activation in monocytes from individuals with alpha-1 antitrypsin deficiency. J Immunol 2010; 184: 4538-4546.

24. Claudio N, Dalet A, Gatti E, Pierre P. Mapping the crossroads of immune activation and cellular stress response pathways. The EMBO journal 2013; 32: 1214-1224.

25. Clavarino G, Claudio N, Couderc T, Dalet A, Judith D, Camosseto V, Schmidt EK, Wenger T, Lecuit M, Gatti E, Pierre P. Induction of GADD34 is necessary for dsRNA-dependent interferon-beta production and participates in the control of Chikungunya virus infection. PLoS pathogens 2012; 8: e1002708.

26. Liao Y, Fung TS, Huang M, Fang SG, Zhong Y, Liu DX. Upregulation of CHOP/GADD153 during coronavirus infectious bronchitis virus infection modulates apoptosis by restricting activation of the extracellular signal-regulated kinase pathway. Journal of virology 2013; 87: 8124-8134. 
27. Woo CW, Cui D, Arellano J, Dorweiler B, Harding H, Fitzgerald KA, Ron D, Tabas I. Adaptive suppression of the ATF4-CHOP branch of the unfolded protein response by toll-like receptor signalling. Nat Cell Biol 2009; 11: 1473-1480.

28. Woo CW, Kutzler L, Kimball SR, Tabas I. Toll-like receptor activation suppresses ER stress factor CHOP and translation inhibition through activation of eIF2B. Nature cell biology 2012; 14: 192-200.

29. Ribeiro CM, Paradiso AM, Schwab U, Perez-Vilar J, Jones L, O'Neal W, Boucher RC. Chronic airway infection/inflammation induces a $\mathrm{Ca} 2+\mathrm{i}-\mathrm{dependent}$ hyperinflammatory response in human cystic fibrosis airway epithelia. The Journal of biological chemistry 2005; 280: 17798-17806.

30. Martino ME, Olsen JC, Fulcher NB, Wolfgang MC, O'Neal WK, Ribeiro CM. Airway epithelial inflammation-induced endoplasmic reticulum $\mathrm{Ca} 2+$ store expansion is mediated by X-box binding protein-1. J Biol Chem 2009; 284: 14904-14913.

31. Blohmke CJ, Mayer ML, Tang AC, Hirschfeld AF, Fjell CD, Sze MA, Falsafi R, Wang S, Hsu K, Chilvers MA, Hogg JC, Hancock RE, Turvey SE. Atypical Activation of the Unfolded Protein Response in Cystic Fibrosis Airway Cells Contributes to p38 MAPK-Mediated Innate Immune Responses. Journal of immunology (Baltimore, Md : 1950) 2012; 189: 5467-5475.

32. Clavarino G, Claudio N, Dalet A, Terawaki S, Couderc T, Chasson L, Ceppi M, Schmidt EK, Wenger T, Lecuit M, Gatti E, Pierre P. Protein phosphatase 1 subunit Ppp1r15a/GADD34 regulates cytokine production in polyinosinic:polycytidylic acidstimulated dendritic cells. Proceedings of the National Academy of Sciences of the United States of America 2012; 109: 3006-3011.

33. Goodall JC, Wu C, Zhang Y, McNeill L, Ellis L, Saudek V, Gaston JS. Endoplasmic reticulum stress-induced transcription factor, $\mathrm{CHOP}$, is crucial for dendritic cell IL-23 
expression. Proceedings of the National Academy of Sciences of the United States of America 2010; 107: 17698-17703.

34. Groskreutz DJ, Babor EC, Monick MM, Varga SM, Hunninghake GW. Respiratory syncytial virus limits alpha subunit of eukaryotic translation initiation factor 2 (eIF2alpha) phosphorylation to maintain translation and viral replication. The Journal of biological chemistry 2010; 285: 24023-24031.

35. Ye J, Kumanova M, Hart LS, Sloane K, Zhang H, De Panis DN, Bobrovnikova-Marjon E, Diehl JA, Ron D, Koumenis C. The GCN2-ATF4 pathway is critical for tumour cell survival and proliferation in response to nutrient deprivation. The EMBO journal 2010; 29: 2082-2096.

36. Rouschop KM, Dubois LJ, Keulers TG, van den Beucken T, Lambin P, Bussink J, van der Kogel AJ, Koritzinsky M, Wouters BG. PERK/eIF2alpha signaling protects therapy resistant hypoxic cells through induction of glutathione synthesis and protection against ROS. Proceedings of the National Academy of Sciences of the United States of America 2013; 110: 4622-4627.

37. Bi M, Naczki C, Koritzinsky M, Fels D, Blais J, Hu N, Harding H, Novoa I, Varia M, Raleigh J, Scheuner D, Kaufman RJ, Bell J, Ron D, Wouters BG, Koumenis C. ER stress-regulated translation increases tolerance to extreme hypoxia and promotes tumor growth. EMBO J 2005; 24: 3470-3481.

38. Rouschop KM, van den Beucken T, Dubois L, Niessen H, Bussink J, Savelkouls K, Keulers T, Mujcic H, Landuyt W, Voncken JW, Lambin P, van der Kogel AJ, Koritzinsky M, Wouters BG. The unfolded protein response protects human tumor cells during hypoxia through regulation of the autophagy genes MAP1LC3B and ATG5. J Clin Invest 2010; 120: 127-141. 
39. Su ZZ, Emdad L, Sarkar D, Randolph A, Valerie K, Yacoub A, Dent P, Fisher PB. Potential molecular mechanism for rodent tumorigenesis: mutational generation of Progression Elevated Gene-3 (PEG-3). Oncogene 2005; 24: 2247-2255.

40. Dalton LE, Clarke HJ, Knight J, Lawson MH, Wason J, Lomas DA, Howat WJ, Rintoul RC, Rassl DM, Marciniak SJ. The endoplasmic reticulum stress marker CHOP predicts survival in malignant mesothelioma. Br J Cancer 2013; 108: 1340-1347. 

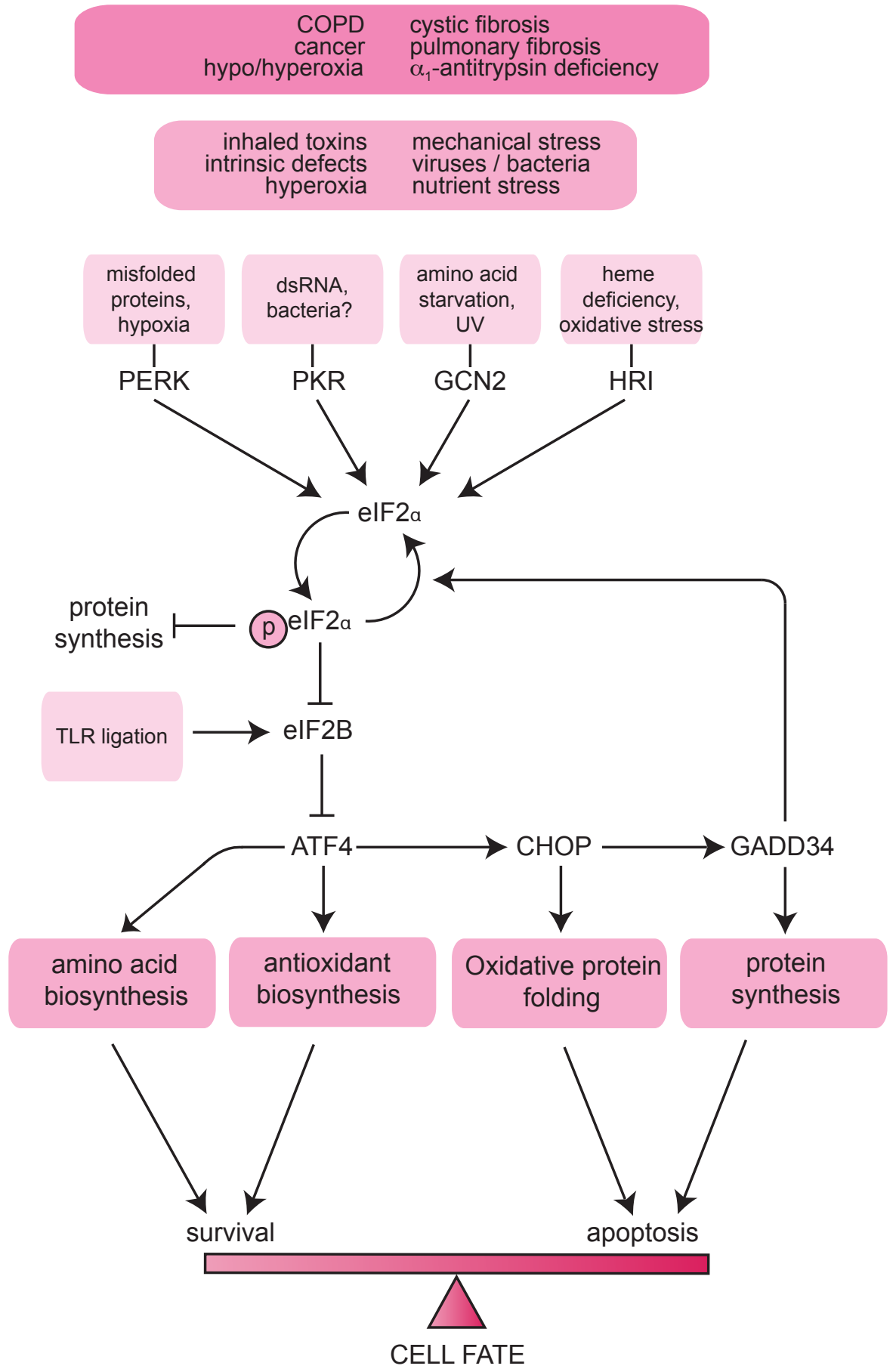